\title{
Memprediksi Faktor Tunggakan Uang Kuliah Menggunakan Metode Naive Bayes
}

\author{
Ledis Pebriani Purba1 ${ }^{1}$, Dedy Hartama², Eka irawan ${ }^{3}$, Anjar Wanto ${ }^{4}$ \\ STIKOM Tunas Bangsa Pematangsiantar \\ Jl.Jenderal Sudirman Blok A No.1/2/3 Pematangsiantar,Medan,Indonesia,21127 \\ ledispebrianipurba@gmail.com
}

\begin{abstract}
Arrears of tuition will be a problem of the operational costs of private universities. In contrast to PTN (State Universities) which are assisted by the government while PTS (Private Universities) rely on tuition to carry out their activities. In carrying out the lecture process STIKOM Tunas Bangsa Students must carry out their obligations to pay tuition in a timely manner so there is no arrears in tuition. In this study, the method used to determine the factor of arrears of tuition is to use the Naive Bayes classification method. The parameters used are 6, namely C1 (Parent Income), C2 (Dependent Income), C3 (Parent Work), C4 (Residential Status), C5 (Money Abuse) and C6 (External Factor). The data used in this study were obtained by giving questionnaires to students of STIKOM Tunas Bangsa Pematangsiantar. Data training used 156 and testing data,and the most factors were external factors. It is expected that the results of this study can be used to help higher education institutions, especially STIKOM Tunas Bangsa education in knowing tuition arrears so that the best solution can be done to reduce the occurrence of tuition arrears.
\end{abstract}

Keywords: Tuition arrears, tuition, Data mining, Naïve Bayes

\begin{abstract}
Abstrak- Tunggakan uang kuliah akan menjadi masalah biaya operasional perguruan swasta. Berbeda dengan PTN (Perguruan Tinggi Negeri) yang dibantu oleh pemerintah sedangkan PTS (Perguruan Tinggi Swasta) mengandalkan uang kuliah untuk menjalankan aktivitasnya. Dalam menjalankan proses perkuliahan STIKOM Tunas Bangsa Mahasiswa harus melaksanakan kewajibannya membayar uang kuliah dengan tepat waktu agar tidak terjadi tunggakan uang kuliah. Dalam penelitian ini, metode yang digunakan untuk mengetahui faktor tunggakan uang kuliah adalah dengan menggunakan metode Naive Bayes klasifikasi. Parameter yang digunakan sebanyak 6 yaitu variabel C1 (Penghasilan Ortu), C2 (Jlh Tanggungan), C3 (Pekerjaan Ortu), C4 (Status Tempat Tinggal), C5 (Penyalahgunaan Uang) dan C6 (Faktor Eksternal). Data yang digunakan dalam penelitian ini didapatkan dengan memberikan kuesioner kepada mahasiswa STIKOM Tunas Bangsa Pematangsiantar. Data traning yang digunakan 156 data dan data testing 16 data,dan faktor terbanyak ialah faktor eksternal. Diharapkan hasil dari penelitian ini dapat digunakan untuk membantu pihak perguruan tinggi khususnya pihak pendidikan STIKOM Tunas Bangsa dalam mengetahui tunggakan uang kuliah sehingga dapat dilakukan solusi yang terbaik untuk mengurangi terjadinya tunggakan uang kuliah.
\end{abstract}

Kata kunci: Tunggakan uang kuliah,uang kuliah, Data mining, Nä̈ve Bayes.

\section{PENDAHULUAN}

Terhambatannya pembayaran uang kuliah sering dialami oleh pihak perguruan tinggi swasta dimanapun, berbeda dengan Perguruan tinggi negeri (PTN) yang banyak mendapat subsidi maupun bantuan dari pemerintah. dikelola oleh Kementerian Riset Teknologi, dan Pendidikan Tinggi Republik Indonesia. Sedangkan perguruan tinggi swasta adalah perguruan tinggi yang dikelola oleh 
Yayasan atau lembaga nonpemerintah. Semua Perguruan Tinggi Swasta di Indonesia dikoordinasikan oleh badan yang disebut Lembaga Layanan Pendidikan Tinggi (L2Dikti). Sekolah tinggi ilmu komputer (STIKOM) yang beralamatkan di Jl. Jendral Sudirman Blok A No. 1,2,3 Pematangsiantar merupakan salah satu perguruan tinggi swasta di Sumatera Utara yang bergerak dibidang komputer dengan prodi Sistem Informasi dan Teknik Informatika. Sebagai Mahasiswa yang aktif mahasiswa harus membayar uang kuliah sebagai tanda kewajiban melaksanakan perkuliahan. Mahasiswa STIKOM Tunas Bangsa Pematangsiantar masih memiliki kendala untuk pembayaran uang kuliah tersebut. ,terjadi tunggakan akan terhambat pula kegiatan operasional sehingga tidak dapat berkembang dan bisa saja mengalami kebangkrutan. Uang kuliah merupakan kewajiban yang harus dilunasi yang sedang melaksanakan perkuliahan guna sebagai media tukar setelah mendapatkan hak dimasa perkuliahan [1].

Tujuan dari penelitian ini adalah membantu bagian keuangan untuk Agar bisa mengatasi pembayaran uang kuliah yang mengalami hambatan. Dengan penelitian yang pernah dilakukan oleh [2] dengan menggunakan Metode Naïve Bayes memanfaatkan data training untuk menghasilkan probabilitas setiap kriteria untuk class yang berbeda sehingga nilai - nilai probabilitas dari kriteria tersebut dengan persentase keakuratan sebesar 78,3333\%. Referensi selanjutnya oleh [3] Penelitian ini menggunakan metode Jaringan Saraf Tiruan Backpropogation dengan menentukan faktor tunggakan uang kuliah dan Penghasilan Orangtua menduduki peringkat paling kecil dari penyebab faktor tunggakan uang kuliah. Tetapi kelemahan yang dihadapi pada algoritma Backprogation tersebut adalah lamanya waktu dan tingkat akurasi prediksi yang digunakan untuk melakukan prediksi. Dengan ini penulis menggunakan metode naive bayes untuk mengatasi kinerja waktu yang lama.

\section{METODOLOGI PENELITIAN}

\section{2.. Metode Pengumpulan Data}

Metode pengumpulan data yang dilakukan yaitu :

a. Penelitian Kepustakaan (Libarry Research) - memanfaatkan perpustakaan, buku, prosiding atau jurnal sebagai media untuk bahan referensi dalam menentukan faktor, parameter dan label yang digunakan untuk penelitian.

b. Kuesioner - Penulis memberikan kuesioner kepada mahasiswa STIKOM Tunas Bangsa Pematangsiantar.

\subsection{Klasifikasi}

Klasifikasi merupakan proses untuk menemukan fungsi dan model yang dapat membedakan atau menjelaskan konsep atau kelas data dengan tujuan memperkirakan kelas yang tidak diketahui dari suatu objek[4].

\subsection{Naive Bayes}

Naïve Bayes melakukan klasifikasi secara efektif dengan mengoptimalkan pengawasan perkiraan dalam probabilitas yang akurat, bahkan ketika asumsi dilanggar performa classifier ini tetap lebih baik dibandingkan classifier yang lain[5]. Naive Bayes merupakan salah satu algoritma Data mining seperti halnya K- 
Means [6]-[9]. Untuk menyelesaikan metode Nä̈ve Bayes dapat dilakukan dengan persamaan-persamaan sebagai berikut:

$P(H \mid X)=\frac{P(X \mid H)^{*} P(H)}{P(X)}$

Keterangan :

$\mathrm{X} \quad$ : Data dengan class yang belum diketahui

$\mathrm{H} \quad$ : Hipotesis data merupakan suatu class spesifik

$\mathrm{P}(\mathrm{H} \mid \mathrm{X})$ : Probabilitas hipotesis $\mathrm{H}$ berdasarkan kondisi $\mathrm{X}$ (posteriori probabilitas)

$\mathrm{P}(\mathrm{H})$ : Probabilitas hipotesis $\mathrm{H}$ (prior probabilitas)

$\mathrm{P}(\mathrm{X} \mid \mathrm{H})$ : Probabilitas $\mathrm{X}$ berdasarkan kondisi pada hipotesis $\mathrm{H}$

$\mathrm{P}(\mathrm{X})$ : Probabilitas $\mathrm{X}$

Penjabaran lebih lanjut rumus Naïve Bayes tersebut dilakukan dengan menjabarkan secara terperinci $\left(\mathrm{C} \mid \mathrm{X}_{1} \ldots, \mathrm{X}_{\mathrm{n}}\right)$ menggunakan aturan perkalian sebagai berikut.

$$
\begin{aligned}
\mathrm{P}\left(\mathrm{C} \mid \mathrm{x}_{1}, \ldots . ., \mathrm{X}_{\mathrm{n}}=\right. & \mathrm{P}(\mathrm{C}) \mathrm{P}\left(\mathrm{x}_{1}, \ldots \ldots, \mathrm{x}_{\mathrm{n}} \mid \mathrm{C}\right) \\
= & \mathrm{P}(\mathrm{C}) \mathrm{P}\left(\mathrm{X}_{1} \mid \mathrm{C}\right) \mathrm{P}\left(\mathrm{X}_{2}, \ldots, \mathrm{X}_{\mathrm{n}} \mid \mathrm{C}, \mathrm{X}_{1}\right) \\
= & (\mathrm{C}) \mathrm{P}\left(\mathrm{X}_{1} \mid \mathrm{C}\right) \mathrm{P}\left(\mathrm{X}_{2} \mid \mathrm{C}, \mathrm{X}_{1}\right) \mathrm{P}\left(\mathrm{X}_{3}, \ldots \mathrm{X}_{\mathrm{n}} \mid \mathrm{C}, \mathrm{X}_{1}, \mathrm{X}_{2}(\mathrm{C}) \mathrm{P}\left(\mathrm{X}_{1} \mid \mathrm{C}\right)\right. \\
& \mathrm{P}\left(\mathrm{X}_{2} \mid \mathrm{C}, \mathrm{X}_{1}\right) \mathrm{P}\left(\mathrm{X}_{3} \mid \mathrm{C}, \mathrm{X}_{1}, \mathrm{X}_{2}\right) \mathrm{P}\left(\mathrm{X}_{4}, \ldots, \mathrm{X}_{\mathrm{n}} \mid \mathrm{C}, \mathrm{X}_{1}, \mathrm{X}_{2}, \mathrm{X}_{3}\right) \mathrm{P}(\mathrm{C}) \\
= & \mathrm{P}\left(\mathrm{X}_{1} \mid \mathrm{C}\right) \mathrm{P}\left(\mathrm{X}_{2} \mid \mathrm{C}, \mathrm{X}_{1}\right) \mathrm{P}\left(\mathrm{X}_{3} \mid \mathrm{C}, \mathrm{X}_{1}, \mathrm{X}_{2}\right) \ldots \\
& \mathrm{P}\left(\mathrm{X}_{\mathrm{n}} \mid \mathrm{C}, \mathrm{X}_{1}, \mathrm{X}_{2}, \mathrm{X}_{3}, \ldots . . \mathrm{X}_{\mathrm{n}-1} \ldots . .\right.
\end{aligned}
$$

Jika semakin banyak faktor-faktor yang semakin kompleks yang berpengaruh terhadap nilai probabilitas, maka semakin tidak mungkin untuk menghitung nilai tersebut satu persatu dengan persamaan 3 :

$P\left(X_{i} \mid X_{j}\right)=\frac{P\left(X_{i}\right) P(X j)}{P(X j)}=\frac{P\left(X_{i} \cap X_{j}\right)}{P\left(X_{j}\right)}=P\left(X_{i}\right)$

Untuk $\mathrm{i} \neq \mathrm{j}$, sehingga

$P\left(X_{i} \mid C, X_{j}=P\left(X_{i} \mid C\right)\right.$

Dari persamaan 2.3 tersebut dapat di ambil kesimpulan bahwa asumsi independensi membuat syarat perhitungan menjadi lebih sederhana. Selanjutnya penjabaran $(P(C / X 1, \ldots . ., X n)$ dapat disederhanakan menjadi persamaan 4 :

$P\left(X_{2} \mid C\right) P\left(X_{3} \mid C\right) \ldots P\left(C \mid X_{1}, \ldots X_{n}\right)=P\left(X_{1} \mid C\right)=\prod_{i=1}^{n} p(X i \mid C)$

Keterangan :

$\prod_{i=1}^{n} P\left(X_{i} \mid C\right)=$ perkalian ranting antar atribut.

Persamaan 4 merupakan teorema bayes yang kemudian akan digunakan untuk melakukan perhitungan klasifikasi. Untuk klasifikasi dengan data continue atau data angka menggunakan rumus distribusi Gaussian dengan 2 parameter : mean $\mu$ dan varian $\sigma$ : 


$$
P\left(X_{i}=X_{i} \mid C=c_{j}\right)=\frac{1}{\sqrt{2 \pi \sigma i j}} \exp \frac{(x i-\mu i j) 2}{2 \sigma 2 i j}
$$

Keterangan :

$\mathrm{P}$ : Peluang

$\mathrm{X}_{\mathrm{i}}$ :Atribut ke

$\mathrm{X}_{\mathrm{j}}$ : Nilai atribut ke $\mathrm{i}$

$\mathrm{C}$ : Kelas yang dicari

$\mathrm{C}_{\mathrm{i}}$ : Sub kelas Y yang dicari

$\mu$ : Menyatakan rata-rata dari seluruh atribut

$\sigma:$ Deviasi standar, menyatakan varian dari seluruh atribut.

Dalam metode Nä̈ve Bayes diperlukan data latih dan data uji yang ingin diklasifikasikan. Semakin banyak data latih yang yang dilibatkan, semakin baik hasil yang prediksi yang diberikan. Menghitung $\mathrm{P}\left(\mathrm{C}_{\mathrm{i}}\right)$ yang merupakan probabilitas prior untuk setiap sub kelas $C$ yang akan dihasilkan menggunakan persamaan 6 :

$$
P(C i)=\frac{S i}{s}
$$

Si adalah jumlah data training dari kategori $\mathrm{Ci}$, dan s adalah jumlah total data training. Menghitung $\mathrm{P}\left(\mathrm{X}_{\mathrm{i}} \mid \mathrm{C}_{\mathrm{i}}\right)$ yang merupakan probabilitas posterior Xi dengan syarat $\mathrm{C}$ menggunakan persamaan 4.

\section{HASIL DAN PEMBAHASAN}

\subsection{Penentuan Kriteria dan Alternatif}

Data yang akan diolah ada data training dan data testing. Data training yang digunakan terdapat 156 data sedangkan data testing terdapat 16 data yang digunakan. Kriteria data yang telah ditentukan dianalisis menggunakan perangkat lunak rapidminer 5.3. data Kuesioner yang akan dianalisis memiliki 172 data.

Tabel 1.Data Penelitian

\begin{tabular}{|c|c|c|c|c|c|}
\hline $\begin{array}{c}\text { Nama } \\
\text { Responden }\end{array}$ & $\begin{array}{c}\text { Penghasilan } \\
\text { Orang Tua }\end{array}$ & $\begin{array}{c}\text { Jumlah } \\
\text { Tanggungan }\end{array}$ & $\begin{array}{c}\text { Pekerjaan } \\
\text { orang tua }\end{array}$ & $\begin{array}{c}\text { Faktor } \\
\text { Eksternal }\end{array}$ & Hasil \\
\hline R1 & S & S & S & TS & YA \\
\hline R3 & SS & SS & N & S & TIDAK \\
\hline R4 & S & SS & SS & SS & TIDAK \\
\hline R5 & SS & SS & TS & SS & YA \\
\hline R6 & S & S & TS & TS & YA \\
\hline R7 & SS & SS & S & SS & TIDAK \\
\hline R8 & SS & S & S & S & TIDAK \\
\hline R9 & N & S & N & TS & YA \\
\hline : & S & S & $:$ & $:$ & $:$ \\
\hline R118 & N & S & TS & N & $?$ \\
\hline R169 & S & SS & S & N & TIDAK \\
\hline R170 & SS & SS & SS & S & YA \\
\hline R171 & S & SS & N & TS & TIDAK \\
\hline R172 & N & N & N & N & TIDAK \\
\hline
\end{tabular}




\subsection{Perhitungan Manual}

Setelah data telah ditentukan, langkah selanjutnya penulis menghitung jumlah YA dan TIDAK berdasarkan gambar 1. Dari 172 data yang digunakan, diketahui kelas Ya (tepat waktu) sebanyak 116 data, dan kelas Tidak tepat waktu sebanyak 39 data. Perhitungan probabilitas kemungkinan tepat waktu dalam dan tidak tepat waktu menentukan faktor tunggakan uang kuliah dilihat pada persamaan (6), yaitu :

Yang Tidak Tepat waktu membayar uang kuliah adalah :

$P$ (Tidak) $=\frac{39}{156}=0,258$

Sedangkan yang tepat waktu adalah :

$P(Y a)=\frac{116}{156}=0,742$

Setelah probabilitas dari masing-masing prior telah diketahui, selanjutnya menentukan probabilitas setiap kriteria, penulis menghitung bagian-bagian yang terdapat pada setiap kriteria, pada penelitian ini bagian-bagian yang terdapat dalam setiap kriteria menggunakan skala linkert 5 yaitu SS,S,N,TS dan STS. Sehingga dalam menentukan probabilitas setiap kriteria dilakukan dengan menghitung jumlah Tepat waktu (YA) dan Tidak tepat waktu (TIDAK) pada skala linkert yang digunakan. Sehingga perhitungan probabilitas masing-masing kriteria dapat dilihat pada beberapa tabel-tabel berikut.

Untuk menghitung probabilitas kemungkinan dari kriteria komunikasi dapat dilihat pada tabel 2 sebagai berikut.

Tabel 2. Probabilitas Penghasilan Orang Tua

\begin{tabular}{|c|c|c|c|c|}
\hline \multirow{2}{*}{$\begin{array}{c}\text { Penghasilan } \\
\text { Orang Tua }\end{array}$} & \multicolumn{2}{|c|}{$\begin{array}{c}\text { Jumlah } \\
\text { Kejadian } \\
\text { Dipilih }\end{array}$} & \multicolumn{2}{|c|}{ Probabilitas } \\
\cline { 2 - 5 } & YA & TIDAK & YA & TIDAK \\
\hline SS & 15 & 12 & 0,1293 & 0,461538462 \\
\hline S & 29 & 14 & 0,2500 & 0,5385 \\
\hline N & 52 & 0 & 0,4483 & 0,0000 \\
\hline TS & 11 & 0 & 0,094827586 & 0 \\
\hline STS & 9 & 0 & 0,077586207 & 0 \\
\hline Jumlah & 116 & 26 & 1 & 1 \\
\hline
\end{tabular}

Untuk menghitung probabilitas kemungkinan dari kriteria Jumlah Tanggungan dapat dilihat pada tabel 3.

Tabel 3. Probabilitas Jumlah Tanggungan

\begin{tabular}{|c|c|c|c|c|}
\hline \multirow{2}{*}{$\begin{array}{c}\text { Jumlah } \\
\text { Tanggungan }\end{array}$} & \multicolumn{2}{|c|}{$\begin{array}{c}\text { Jumlah Kejadian } \\
\text { Dipilih }\end{array}$} & \multicolumn{2}{c|}{ Probabilitas } \\
\cline { 2 - 5 } & YA & TIDAK & YA & TIDAK \\
\hline SS & 11 & 0 & 0,0948 & 0,0000 \\
\hline S & 41 & 0 & 0,3534 & 0,0000 \\
\hline N & 45 & 10 & 0,3879 & 1,0000 \\
\hline
\end{tabular}




\begin{tabular}{|c|c|c|c|c|}
\hline \multirow{2}{*}{$\begin{array}{c}\text { Jumlah } \\
\text { Tanggungan }\end{array}$} & \multicolumn{2}{|c|}{$\begin{array}{c}\text { Jumlah Kejadian } \\
\text { Dipilih }\end{array}$} & \multicolumn{2}{c|}{ Probabilitas } \\
\cline { 2 - 5 } & YA & TIDAK & YA & TIDAK \\
\hline TS & 8 & 0 & 0 & 0,0000 \\
\hline STS & 11 & 0 & 0,094827586 & 0 \\
\hline Jumlah & 116 & 10 & 1 & 1 \\
\hline
\end{tabular}

Untuk menghitung probabilitas kemungkinan dari kriteria Pekerjaan Orang Tua dapat dilihat pada tabel 4.

Tabel 4. Probabilitas Pekerjaan Orang Tua

\begin{tabular}{|c|c|c|c|c|}
\hline $\begin{array}{c}\text { Pekerjaan } \\
\text { Orang } \\
\text { Tua }\end{array}$ & \multicolumn{2}{|c|}{$\begin{array}{c}\text { Jumlah Kejadian } \\
\text { Dipilih }\end{array}$} & \multicolumn{2}{c|}{ Probabilitas } \\
\cline { 2 - 5 } & YA & TIDAK & YA & TIDAK \\
\hline SS & 6 & 0 & 0,0517 & 0,0000 \\
\hline S & 24 & 11 & 0,2069 & 0,5789 \\
\hline N & 36 & 0 & 0,3103 & 0,0000 \\
\hline TS & 38 & 7 & 0 & 0,3684 \\
\hline STS & 12 & 1 & 0,103448276 & 0,052631579 \\
\hline Jumlah & 116 & 19 & 1 & 1 \\
\hline
\end{tabular}

Untuk menghitung probabilitas kemungkinan dari kriteria Faktor Ekternal dapat dilihat pada tabel 5 .

Tabel 5. Probabilitas Faktor Eksternal

\begin{tabular}{|c|c|c|c|c|}
\hline \multirow{2}{*}{$\begin{array}{c}\text { Faktor } \\
\text { Eksternal }\end{array}$} & \multicolumn{2}{|c|}{ Jumlah Kejadian Dipilih } & \multicolumn{2}{c|}{ Probabilitas } \\
\cline { 2 - 5 } & YA & TIDAK & YA & TIDAK \\
\hline SS & 7 & 4 & 0,0603 & 0,102564103 \\
\hline S & 14 & 6 & 0,1207 & 0,1538 \\
\hline N & 37 & 13 & 0,3190 & 0,3333 \\
\hline TS & 42 & 14 & 0,362068966 & 0,3590 \\
\hline STS & 16 & 2 & 0,137931034 & 0,051282051 \\
\hline Jumlah & 116 & 39 & 1 & 1 \\
\hline
\end{tabular}

Setelah masing-masing probabilitas kriteria telah diketahui, langkah selanjutnya adalah menghitung nilai dari salah satu nilai yang diberikan responden untuk menentukan nilai klasifikasi.

$\mathrm{P}(157 \mid \mathrm{YA})=\mathrm{P}($ Penghasilan Orang tua $=\mathrm{SS} \mid \mathrm{YA}) \mathrm{x} \mathrm{P}($ Jumlah Tanggungan $=\mathrm{S} \mid \mathrm{YA}) \mathrm{x}$ $\mathrm{P}($ Pekerjaan Orangtua $=\mathrm{N} \mid \mathrm{YA}) \times \mathrm{P}($ Faktor Ekternal=TS $\mid \mathrm{YA})$

$=0.1293 \times 0.3534 \times 0.3103 \times 0.1379$

$=0.00196$.

$\mathrm{P}(158 \mid \mathrm{YA})=\mathrm{P}($ Penghasilan Ortu $=\mathrm{N} \mid \mathrm{YA}) \mathrm{x} \quad \mathrm{P}($ Jumlah Tanggungan $=\mathrm{S} \mid \mathrm{YA}) \mathrm{x}$

$\mathrm{P}($ Pekerjaan Orang Tua $=\mathrm{S} \mid \mathrm{YA}) \times \mathrm{P}($ Faktor Ekternal $=\mathrm{STS} \mid \mathrm{YA})$

$=0.4483 \times 0.3534 \times 0.2069 \times 0.1379$

$=0,00452$. 
Sedangkan untuk menghitung nilai TIDAK pada data ke-101 sampai dengan 172 rumus yang digunakan sama dengan rumus untuk menentukan nilai YA. Sehingga untuk mendapatkan nilai dilakukan sebagai berikut :

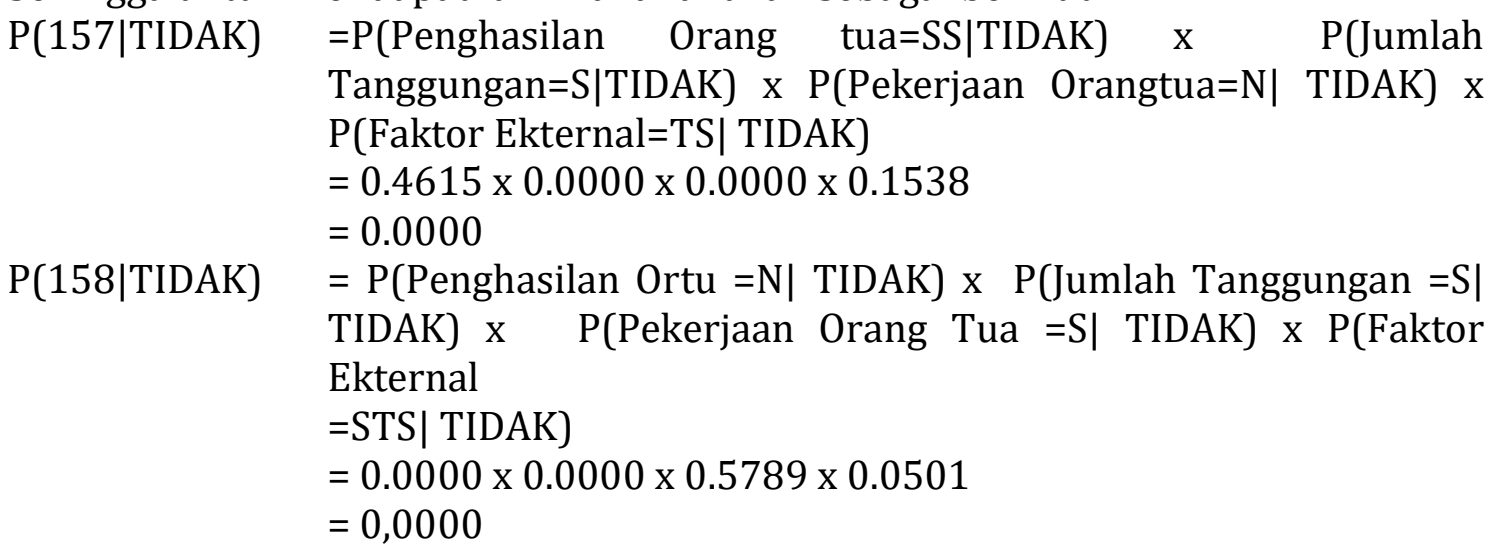

Dan begitu seterusnya sampai dengan P(172| TIDAK).

Setelah nilai YA dan TIDAK pada data 157 sampai dengan 172 telah diketahui. Selanjutnya penulis melakukan perhitungan maksimal masing-masing klasifikasi. Perhitungan data responden 157 sampai dengan 172 untuk menghitung pemaksimalan nilai puas yaitu:

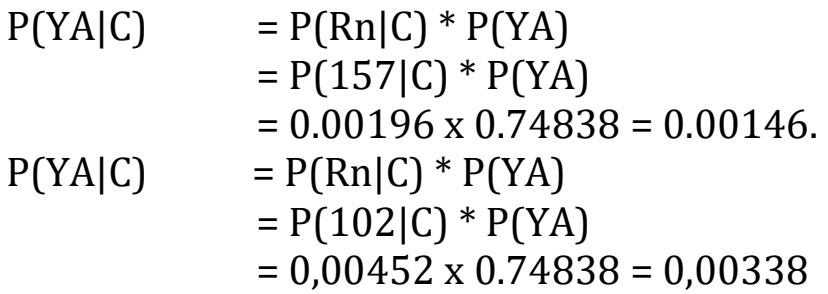

Dan begitu seterusnya sampai dengan data ke 172 .

Sedangkan perhitungan maksimal nilai TIDAK pada data responden 157 sampai dengan 172 yaitu :

$$
\begin{aligned}
\mathrm{P}(\text { Tidak } \mid \mathrm{C}) & =\mathrm{P}(\mathrm{Rn} \mid \mathrm{C}) * \mathrm{P}(\text { TIDAK }) \\
& =\mathrm{P}(101 \mid \mathrm{C}) * \mathrm{P}(\text { TIDAK }) \\
& =0.0000 \times 0,2516 \\
& =0.0000 . \\
\mathrm{P}(\text { Tidak } \mid \mathrm{C}) & =\mathrm{P}(\mathrm{Rn} \mid \mathrm{C}) * \mathrm{P}(\text { TIDAK }) \\
& =\mathrm{P}(102 \mid \mathrm{C}) * \mathrm{P}(\text { TIDAK }) \\
& =0.0000 \times 0,2516 \\
& =0.0000 .
\end{aligned}
$$

Dan begitu seterusnya sampai dengan data ke 172.

Setelah menghitung pemaksimalan dari nilai YA dan TIDAK, selanjutnya penulis membandingkan nilai YA dan TIDAK. Sehingga dapat diketahui mahasiswa tersebut termasuk kedalam kategori tepat waktu atau tidak tepat waktu.

$$
\begin{aligned}
\mathrm{R} 101 & =\mathrm{YA}>=\text { TIDAK } \\
& =0.00146 .>=0.0000 \\
& =0.00146(\mathrm{YA}) .
\end{aligned}
$$




$$
\begin{aligned}
\mathrm{R} 102 & =\mathrm{YA}>=\text { TIDAK } \\
& =0,00338>=0.0000 \\
& =0.0000(\mathrm{YA}) .
\end{aligned}
$$

Dan begitu seterusya hingga responden 172 Sehingga dapat diketahui bahwa data testing dari data responden 157-172 memiliki klasifikasi YA(tepat waktu).

\subsection{Validasi Data Kuisioner dengan SPSS}

Analisa data ini dilakukan pemodelan data kuisioner validasi data Cross Alpha menggunakan program SPSS. Dengan mengunakan program ini analisa data yang dilakukan akan lebih efektif dan efesien karena fitur yang ada, SPSS adalah sebuah software komputer yang salah satu fungsinya adalah untuk menghitung data statistik (Wiratna, V. 2014).

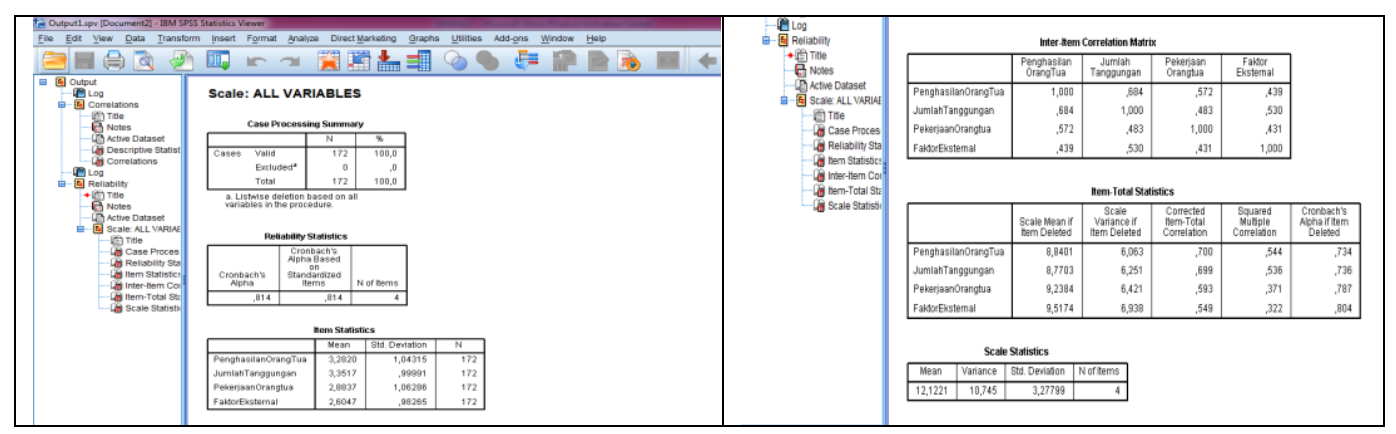

Gambar 1.Tampilan data UJI SPSS

\subsection{Implementasi Klasifikasi Naive Bayesian Pada Rapid Miner}

Berikut ini adalah pengolahan data dengan menggunakan naive bayesian pada Rapid Miner :

Dengan menggunakn pemodelan klasifikasi naive bayesi seperti gambar di atas dengan mengklasifikasi 2 jenis klasifikasi yaitu YA dan TIDAK. Kemudian Berikut ini adalah hasil implementasi dari gambar diatas.

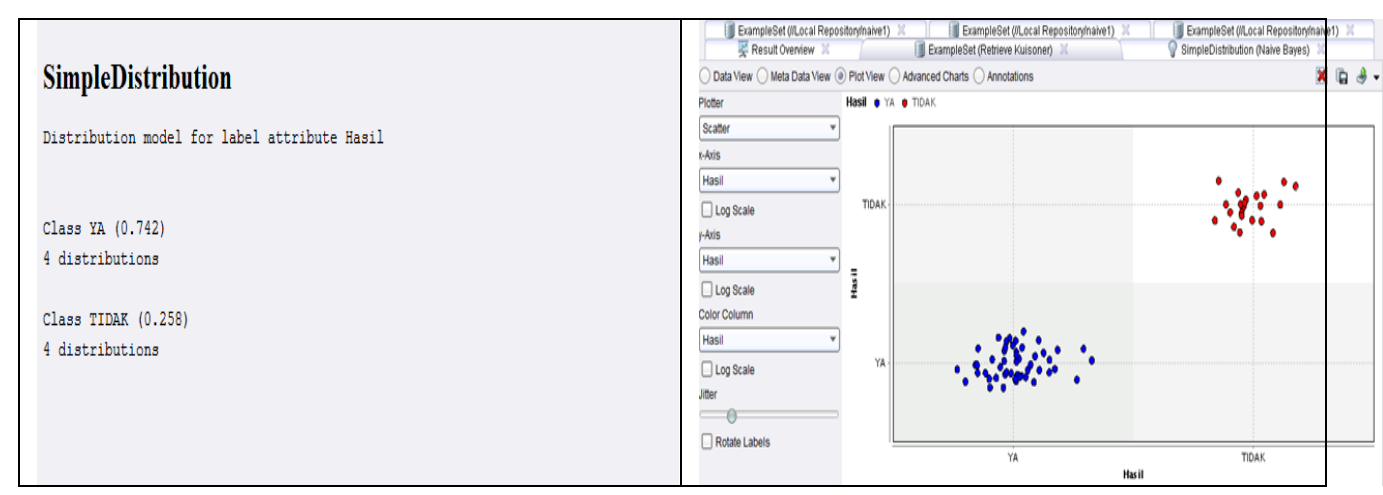

Gambar 2. Hasil Klasifikasi

\section{KESIMPULAN}

Berdasarkan hasil penelitian dan pembahasan yang telah dilakukan, dapat disimpulkan bahwa algoritma Naive Bayesian Classification (NBC) dapat digunakan 
sebagai salah satu metode untuk klasifikasi dalam menentukan faktor tunggakan uang kuliah di STIKOM Tunas Bangsa Pematangsiantar dengan parameter yang digunakan dalam penelitian ini yaitu Penghasilan Orang tua, Jumlah Tanggungan, Pekerjaan Orang tua dan Faktor Ekternal. Berdasarkan 156 data training yang diolah di dalam Rapidminer, hasil pengujian menunjukkan akurasi sebesar $62,63 \%$ yaitu 39 responden menyatakan Tidak disiplin membayar uang kuliah dan 116 responden menyatakan disiplin atau melaksanakan pembayaran uang kuliah dengan tepat waktu. Dengan class precision pada prediksi Tidak memiliki nilai $60.34 \%$, sedangkan pada prediksi Ya memiliki nilai $69.03 \%$. Class recall pada true Ya memiliki nilai 85.37 \%, sedangkan pada true Tidak memiliki nilai $36.99 \%$. Sehingga dapat dikatakan bahwa faktor mahasiswa yang mengalami tunggakan uang kuliah adalah dari 4 yaitu variabel C1 (Penghasilan Ortu), C2 (Jumlah Tanggungan), C3 (Pekerjaan Ortu), dan C4 (Faktor Eksternal) faktor terbesar ialah Faktor eksternal dengan hasil 0,804.

\section{DAFTAR PUSTAKA}

[1] S. Endriani, “ISSN 1412-1395 (cetak) 2355-3529 (elektronik),” vol. 15, pp. 70-75, 2015.

[2] A. Saleh, "Implementasi Metode Klasifikasi Naïve Bayes Dalam Memprediksi Besarnya Penggunaan Listrik Rumah Tangga," no. January 2015, 2016.

[3] A. P. Windarto, D. Hartama, and N. Dalimunthe, "Model Arsitektur Backpropogation Dalam Memprediksi Faktor Tunggakan Uang Kuliah (Studi Kasus AMIK Tunas Bangsa)," in Seminar Nasional Multidisiplin, 2017, pp. 1-9.

[4] Y. sulistio Nugroho, "Penerapan Algoritma C4.5 untuk Klasifikasi Predikat Kelulusan Mahasiswa Fakultas Komunikasi dan Informatika Universitas Muhammadiyah Surakarta," Prosiding Seminar Nasional Aplikasi Sains \& Teknologi (SNAST), no. November, pp. 1-6, 2014.

[5] C. Fadlan, S. Ningsih, and A. P. Windarto, "PENERAPAN METODE NAÏVE BAYES DALAM KLASIFIKASI KELAYAKAN KELUARGA PENERIMA BERAS RASTRA,” JUTIM, vol. 3, no. 1, pp. 1-8, 2018.

[6] I. Parlina, A. P. Windarto, A. Wanto, and M. R. Lubis, "Memanfaatkan Algoritma K-Means dalam Menentukan Pegawai yang Layak Mengikuti Asessment Center untuk Clustering Program SDP," CESS (Journal of Computer Engineering System and Science), vol. 3, no. 1, pp. 87-93, 2018.

[7] M. G. Sadewo, A. P. Windarto, and A. Wanto, "Penerapan Algoritma Clustering dalam Mengelompokkan Banyaknya Desa/Kelurahan Menurut Upaya Antisipasi/ Mitigasi Bencana Alam Menurut Provinsi dengan K-Means," KOMIK (Konferensi Nasional Teknologi Informasi dan Komputer), vol. 2, no. 1, pp. 311-319, 2018.

[8] S. Sudirman, A. P. Windarto, and A. Wanto, "Data Mining Tools | RapidMiner: K-Means Method on Clustering of Rice Crops by Province as Efforts to Stabilize Food Crops In Indonesia," IOP Conference Series: Materials Science and Engineering, vol. 420, no. 12089, pp. 1-8, 2018.

[9] R. W. Sari, A. Wanto, and A. P. Windarto, "Implementasi Rapidminer dengan Metode K-Means (Study Kasus: Imunisasi Campak pada Balita Berdasarkan Provinsi)," KOMIK (Konferensi Nasional Teknologi Informasi dan Komputer), vol. 2, no. 1, pp. 224-230, 2018.

[10] T. Badan, J. Hb, and M. A. Posteriori, "Klasifikasi Naïve Bayes untuk Prediksi Kelahiran pada Data Ibu Hamil," vol. 23, no. September, pp. 297-308, 2013. 